\title{
Ethical Considerations About Spirituality in Social Work: Insights From a National Qualitative Survey
}

\author{
Edward R. Canda, Mitsuko Nakashima, \& Leola Dyrud Furman
}

\begin{abstract}
A mixed methods national survey of 2,069 National Association of Social Workers members examined ethical concerns regarding religious and nonreligious spiritual issues in clinical practice settings. This qualitative study focuses on responses to open-ended survey questions and relates them to quantitative findings. Practitioners' insights provide a basis to extend ethical guidelines in practice and education. The findings indicate that most respondents deal with spirituality in practice, and many use general ethical principles and situational considerations. However, they likely lack guidelines for systematic ethical decision making about the use of spiritually oriented activities in practice. The authors suggest ways that social work educators and supervisors should provide ethical guidelines and case examples for spiritually oriented activities in both educational and direct practice contexts.
\end{abstract}

nterest in spirituality and social work expanded rapidly recently, as shown by a significant increase in the number of articles and books published in the past 10 years (Canda, Nakashima, Burgess, Russel, \& Barfield, 2003), the recent establishment of a spirituality symposium at the Annual Program Meeting of the Council of Social Work Education (CSWE; Sheridan, 2000) and a Web site on spirituality sponsored by CSWE, the fifty-plus schools that offer Master of Social Work courses on spirituality (R. Russel, personal communication, May 18, 2001), and continuing empirical investigations of the views of social workers about religion and spirituality since the late 1980s (e.g., Canda \& Furman, 1999; Derezotes \& Evans, 1995; Dudley \& Helfgott, 1990; Joseph, 1988; Sheridan \& Amato-von Hemert, 1999; Sheridan, Bullis, Adcock, Berlin, \& Miller, 1992; Sheridan, Wilmer, \& Atcheson, 1994).
However, despite this growing interest, there has been very litthe discussion about ethical guidelines for social workers to address issues of spirituality in practice and education. This is puzzling considering the controversies evoked by the topic of spirituality among social workers, especially regarding such ethical concerns as inappropriate proselytization, imposition of religious beliefs or activities (such as prayer) on clients, and bias against various spiritual perspectives (Canda \& Furman, 1999). To contribute to further development of ethical guidelines, this article summarizes insights about ethical considerations for addressing spirituality (in both religious and nonreligious forms) from the first representative mixed methods national survey of National Association of Social Workers (NASW) clinical practitioner members ( $N=2,069 ; 26 \%$ response rate). The survey methods' details and many findings from the quantitative portion of the survey were presented in Canda and Furman (1999). 
This article focuses on previously unreported responses to qualitative open-ended questions that reflect the way respondents use ethical considerations regarding the decision of whether and how to address spirituality in practice. Methodological details about the qualitative portion of this study are reported later in this article. Relevant findings from a statistical analysis of the quantitative survey items are also presented. Finally, implications for social work education and practice about ethics and spirituality are discussed.

\section{Previous Studies on Ethics and Spirituality in Social Work}

Regional and national survey studies have revealed that the majority of social worker respondents (students, faculty, and practitioners) value the spiritual dimension of their own lives and believe in its importance for their clients (Bullis, 1996; Canda \& Furman, 1999; Derezotes \& Evans, 1995; Joseph, 1988; Mattison, Jayaratne, \& Croxton, 2000; Sheridan \& Amato-von Hemert, 1999; Sheridan et al., 1992; Sheridan et al., 1994). These studies indicate that most of their respondents reported that they incorporate various spiritually oriented activities into work with clients. Reported helping practices range from making referrals to clergy and gathering information on clients' spiritual backgrounds to more controversial methods, such as touching clients for healing purposes and using prayer. It is alarming that the majority of respondents in these studies also reported that they had little or no educational preparation for how to deal with spirituality. This raises concern about competence regarding relevant knowledge, skills, and preparation to make practice decisions that conform to professional ethics. A regional study by Sheridan (2000) indicated that respondents did not consistently use systematic standards or procedures for ethical decision making about spiritually oriented interventions such as those described by Canda (1990a) and Canda and Furman (1999).

Several social work writers have discussed ethical considerations in addressing spirituality in practice. Textbooks on spirituality and religion in social work share broad professional ethical principles for addressing spirituality in social work (Bullis, 1996; Canda \& Furman, 1999; Cnaan, Wineburg, \& Boddie, 1999; Ellor, Netting, \& Thibault, 1999; Loewenberg, 1988; Nash \& Stewart, 2002; Patel, Naik, \& Humphreys, 1997; Van Hook, Hugen, \& Aguilar, 2001), including being nonjudgemental, client self-determination, unconditional positive regard, informed consent, worker competency, promotion of justice, and countering discrimination and oppression. These ethical themes are consistent with issues raised by practitioners in regional qualitative studies (Sheridan, 2000; Sheridan \& Bullis, 1991) and by educator-authors in a national qualitative survey (Canda, 1990b). These texts and empirical studies offer various examples of how these principles should apply to spiritual assessment, clinical interventions, referral, and legal issues of church-and-state separation. Anderson (1983), York (1987), and Linzer (1999) discussed how social workers could deal with ethical dilemmas relating to religious patients' concerns about medical directives, life-sustaining options, assisted suicide, and long-term care. Sherwood (1998) argued that good practice principles in spiritual assessment and intervention rest on the worker's ability to tune into each unique helping process as it is influenced by the client's life situation and spiritual background, the worker's spiritual background, and the agency setting.

These studies have laid valuable groundwork for general ethical principles and provided empirically based information about practitioners' opinions. However, with the exception of the Canda and Furman (1999) book, none of these works provided systematic guidelines for ethical decision making focused on spirituality. To extend development of ethical guidelines for addressing spirituality in practice, this study connects insights grounded in practitioners' own experience and advice with the Canda and Furman ethical framework. The authors obtained permission to use previously unpublished qualitative data from the Canda and Furman national NASW members survey and to analyze it for this purpose. These qualitative data provide the most indepth view of practitioners' ethical decision making about spirituality to date.

\section{Method}

This qualitative study analyzes handwritten responses to three open-ended questions that were included in the Canda and Furman (1999) national survey of NASW practitioner members about their attitudes and practices regarding spirituality and religion. For the purpose of this survey, religion was defined as "an organized, structured set of beliefs and practices shared by a community, related to spirituality"; and spirituality was defined as "involving the search for meaning, purpose, and morally fulfilling relations with self, other people, the encompassing universe and ultimate reality, however a person understands it" (Canda \& Furman, 1999, p. 316). People may express their spirituality through religious or nonreligious forms and settings; therefore, the term spirituality encompasses religion but is not limited to it. The survey often asked a given question in relation to both the narrower term religion and the more inclusive term spirituality in order to explore whether responses would vary.

The survey included 105 items, 102 of which were closedended quantitative-type questions that were analyzed statistically. The three open-ended questions allowed respondents to comment on issues raised by the quantitative items with explanations, examples, and reactions. These three questions asked respondents to share views on (a) the relevancy of religious and spiritual issues of practice to education, (b) appropriate and inappropriate uses of religion and spirituality in social work practice, and (c) other issues related to the topic.

Of 8,000 surveyed, 2,069 people returned questionnaires for a 26\% response rate (see Canda \& Furman, 1999, Appendix $B$, for details on reliability and validity of the 
quantitative portion of the survey). The first, second, and third open-ended questions were answered, respectively, by $1,295,1,398$, and 964 respondents (i.e., percentages of all responders: Question 1 =63\%, Question 2 $=66 \%$, Question $3=47 \%$ ). All responses were coded and sorted according to themes that reflected the topics of the various quantitative items, ethical issues implied in the Canda and Furman (1999) framework, and other themes that were developed inductively from review of responses by the research team. The constant comparative method and ATLAS-ti software for qualitative data analysis were used for this purpose (Erlandson, Harris, Skipper, \& Allen, 1993). This resulted in a massive amount of sorted responses. For the purpose of this study, material was extracted from codes that relate to ethical decision making regarding respondents' use of spirituality in practice. This includes comments about why people believed it was appropriate or inappropriate to engage in particular spiritually oriented practices in social work (such as spiritual assessment or prayer), and what ethical considerations led them to actually engage in or refrain from dealing with spirituality in practice.

It should be noted that these qualitative responses are not necessarily statistically representative of social workers'
An overwhelming majority

(236) supported the inclusion

of religious and spiritual content

in social work education. Those

who supported inclusion gave

a wide range of rationales. forms were typed under the supervision of Leola Dyrud Furman. The typed responses were double checked for accuracy by all three members of the research team at various stages. Apparent errors or ambiguous items were referred back to the typist and corrected or indicated with a question mark. Only unambiguous entries were used for this analysis. Edward R. Canda and Mitsuko Nakashima devised a tentative coding guide and revised it until mutual agreement was achieved about the meaning of code categories and how they were applied to specific comments for coding. Mitsuko Nakashima assumed the task of coding and sorting all the material and formulating analysis summaries, under the supervision of Edward R. Canda. Both authors continued discussion about coding decisions throughout all stages of the analysis until they were in agreement. Findings, including numbers of comments that relate to particular quantitative items (such as appropriateness of assessing spirituality), were compared with the frequencies of responses to the relevant quantitative items. Tentative conclusions of Edward R. Canda and Mitsuko Nakashima were again checked with Leola Dyrud Furman, who inspected them in relation to both the quantitative and qualitative data. Although it is not necessarily the case that people would choose to comment simviews nationally, even though the total sample appeared to be representative of the NASW practitioner members overall. This is because respondents to the quantitative portion of the survey could choose whether to respond to the openended questions in many different ways. The intention is not to make statistical generalizations from this qualitative study, but rather to tap the wealth of insights from the numerous respondents in the largest national pool of social work practitioners ever to discuss spirituality. In keeping with standards for transferability (i.e., broad usability) of qualitative research findings (Lincoln \& Guba, 1985), the usefulness of these insights is enhanced by the large number of respondents with national distribution, comparison of both the quantitative and qualitative portions of findings, provision of details of survey respondents' ideas that can be useful for readers' own reflection on ethical issues, linkage of respondents' insights with discussion of ethical guidelines in social work literature, and elaboration of implications for practice and education.

Several measures were taken to support additional aspects of the trustworthiness and methodological rigor of this analysis (Erlandson et al., 1993; Marshall \& Rossman, 1999). All written responses to open-ended questions on survey ilarly to the frequencies for a quantitative item, the fact that similar emphasis appeared in both quantitative and qualitative forms added confidence that the coding approach made sense. In addition to these procedures, the research team maintained an audit trail of research materials that allows the tracing of any conclusions back to original survey forms and documents methodological decisions and activities.

This article organizes findings according to subthemes under three major thematic topics: competence and educational preparation to address spirituality, ethical considerations for performing specific spiritually oriented helping activities, and ethical decision-making guidelines. As relevant, discussion of these qualitative findings refer to quantitative findings, as reported in the Canda and Furman (1999) text.

\section{Findings}

\section{Ethical Reflections About Competence and Social Work Education}

Two hundred fifty respondents commented on how spiritual issues should be addressed in a social work educational degree program. An overwhelming majority (236) supported the inclusion of religious and spiritual content in 


\title{
Supporters identified these activities as being helpful to some clients,
}

\author{
but typically, this support was situational, not unequivocal. In other words, \\ respondents indicated that these interventions should be used in consonance
}

with clients' interests and goals.

social work education. Those who supported inclusion gave a wide range of rationales. Most of these can be summarized under the three most frequent reasons: A variety of religious and/or nonreligious spiritual beliefs and practices should be understood in the context of human diversity; knowledge about negative and positive impacts of religious and nonreligious forms of spirituality is critical to understanding human behaviors and coping; and ethical issues of handling spiritual issues in practice should be discussed. Many respondents considered that courses on social work practice, human behavior and the social environment, and electives are areas of curriculum in which the subjects of religion and spirituality can be readily integrated. Only 7 respondents voiced opposition to the inclusion of such content in social work education. They stated that religion and spirituality are not relevant to social work education.

Ten of the respondents noted that their own social work program either integrated content about religious or nonreligious aspects of spirituality into the entire program or included a special course on the topic. Of these, 7 respondents added they were able to apply this knowledge to their practice.

However, the majority of comments on education indicated the inadequacy of social work education in addressing the subject because of educators omitting the content or expressing negative attitudes toward bringing up such matters in the classroom. As a consequence, some people sought further education or training through a pastoral degree, other departments that offered related subjects, and continuing education workshops and private supervision. These findings are consistent with the quantitative portion of survey data in which $73 \%$ of respondents reported they did not have content on spirituality or religion in their social work education. Even clinical practice, practicum, and diversity courses exposed only $12 \%-13 \%$ of respondents to this topic. Only $17 \%$ agreed that social workers in general have the knowledge to address such issues (Canda \& Furman, 1999, pp. 73-74).

In keeping with the ethical mandate for competence, 332 people commented on the importance of the social worker gaining necessary skills, knowledge, and professional qualifications in order to engage in spiritually sensitive practice.
Following are the most common types of comments: (a) "Worker needs to be familiar with different religious and nonreligious spiritual belief systems and practices from the standpoint of human diversity"; (b) "Worker needs to develop understanding of how religion and spirituality may have negative and positive impacts on human life"; (c) "Worker needs to be trained to develop skills to work in the area of religious and spiritual content"; (d) "Worker needs to develop knowledge of religion and spirituality regarding human development"; (e) "Worker should not address issues of religion or spirituality if one does not have qualification as a religious counselor"; (f) "Worker needs to have supervision or consultation to work on religious and spiritual issues with clients"; (g) "Worker needs to be licensed as a religious (or pastoral) counselor to provide counseling related to these issues"; (h) "Worker needs to stay out of these issues if one does not have enough knowledge and training"; (i) "Worker needs to be competent to distinguish psychopathology from religious experiences."

\section{Ethical Reflections About Specific Professional Helping Activities}

Assessment. Four quantitative items asked respondents about general assessment of spiritual and religious aspects of clients' lives, both whether they have done so personally and whether they believe this is an appropriate social work helping activity (Canda \& Furman, 1999, p. 261). Eighty-one percent have discussed the role of clients' religious or spiritual beliefs in relation to significant others, and $90 \%$ believe this is appropriate. Sixty-four percent have assisted clients with reflecting critically on religious or spiritual beliefs or practices, and $77 \%$ believe this is appropriate. Ninety-four percent have helped clients consider ways their religious or spiritual systems are helpful, and $97 \%$ agreed this is appropriate. Seventy-one percent of respondents helped clients to consider ways their religious or spiritual systems are harmful, and $87 \%$ agreed this is appropriate.

This strongly positive view of spiritual assessment was also reflected in the qualitative data. Eighty-five people's comments supported addressing spirituality in initial assessment, 
and only 2 people commented in opposition to it. Four hundred sixty-eight people commented favorably on appropriate situations for gathering information about spirituality and religion, and only 12 people expressed opposition to this. In general, assessment and information gathering about spirituality and social work were approved as ways of learning about positive or negative impacts of religious or nonreligious spiritual activities, beliefs, and support systems. Those few who objected felt that this entire subject was beyond the scope of social work and should be referred to religious specialists if dealt with at all. A more detailed examination of comments about initial assessment illustrates respondents' ethical considerations.

Many respondents simply wrote briefly that it is appropriate to assess clients' spiritual views. Some indicated their reasons for incorporating discussion of spirituality into the initial assessment, which include (a) to identify spiritually (religious and nonreligious) based strengths, supports, and resources for coping as part of a comprehensive psychosocial understanding of the client; (b) to discern spiritual aspects of the healing and recovery process, especially for clients dealing with issues of crisis, loss, death, trauma, substance abuse, and serious illness; (c) to deepen knowledge about dynamics relating to cultural diversity; (d) to understand the relevance of spirituality to development over the life span; (e) to evaluate harms and vulnerabilities brought on by spirituality, especially in religious forms; (f) to differentiate symptoms of psychopathology from nonpathological spiritual needs and experiences expressed by clients; (g) to shed light on the context of presenting problems; (h) to determine whether spirituality should be addressed in further treatment; (i) to learn what, if any, meaning and beliefs that clients derive from spirituality; (j) to learn moral, ethi$\mathrm{cal}$, and value orientations of clients that affect their life decisions; ( $\mathrm{k}$ ) to learn the degree of importance of spirituality in clients' lives; (l) to treat clients as whole persons.

These reasons supporting spiritual assessment suggest that the ethical principles of starting where the client is, upholding the dignity of the person, cultural competency, and basing practice on carefully gleaned information guide many respondents. In addition, many respondents emphasized that spiritual assessment should only occur with respect for client self-determination. Forty-six of the people commenting favorably on initial assessment stressed that the social worker should never impose one's own values, religious beliefs, or religious agenda on the client. Respondents emphasized the need for being nonjudgmental, ascertaining client interest in pursuing spirituality before going further, refraining from efforts to evangelize or convert clients to one's own religion, avoiding demeaning criticisms of clients' religious beliefs, exercising caution not to exacerbate religiously related delusions or vulnerabilities, and obtaining necessary training and agency support for addressing spirituality.

Appropriateness of specific helping activities. Respondents addressed a variety of spiritually oriented helping activities. Table 1 summarizes, for the most commonly mentioned types
TABLE 1. Commonly Mentioned Types

of Spiritually Oriented Helping Activities

\begin{tabular}{lcc}
\hline TYPE OF ACTIVITY & SUPPORTERS & OPPONENTS \\
\hline Making clergy referrals; collaboration & 129 & 0 \\
Using prayer, meditation, visualization, etc. & 47 & 22 \\
Using rituals and symbols & 16 & 4 \\
Using inspirational readings & 13 & 5 \\
Touching clients for helping purpose & 12 & 5 \\
Using spiritual narrative and dialogue & 10 & 0 \\
Recommending spiritual activities & 10 & 0 \\
Using religious language & 2 & 0 \\
\hline
\end{tabular}

of activities, the number of people who supported various activities and those who opposed them in their comments.

In general, many more people commented in support of engaging in some type of spiritually oriented helping activities than those who opposed them. Supporters identified these activities as being helpful to some clients, but typically, this support was situational, not unequivocal. In other words, respondents indicated that these interventions should be used in consonance with clients' interests and goals. Given their frequently mentioned caution about not imposing beliefs and the limitations of the social workers' qualifications to deal with spirituality, it is not surprising that the most frequently promoted helping activity was referral to or collaboration with religious helping professionals, such as clergy and support systems. No one commented in opposition to this.

The reasoning of respondents can be illustrated by closer examination of three of the most controversial activities, as shown in both quantitative and qualitative data: use of prayer, healing touch, and self-disclosure. In the quantitative survey (see Table 8.1 of Canda \& Furman, 1999, p. 261), 58\% of respondents indicated they privately prayed for clients, and $71 \%$ viewed this as appropriate. Only $28 \%$ said they had actually prayed with clients, and $52 \%$ thought this was appropriate. In the qualitative responses (see Table 1), prayer, meditation, visualization, guided imagery, and biofeedback appeared most commonly as specific spiritually focused activities in which the social worker might directly impinge on the client and therefore generated both supporting and opposing comments. In this category, most people commented about prayer (33 in support, 22 completely opposed). Comments about how people used prayer in social work practice included praying with clients (10), praying for clients privately (9), suggesting prayer to clients (6), praying for clients after notifying them (2), offering a prayer for coworkers (1), praying for oneself (the social worker) to have understanding of the client (1), engaging in group prayer with employees in a religiously sponsored agency (1), facilitating a prayer-based activity in a group (1).

Several people offered qualifying conditions under which prayer would be appropriate. These conditions included client requests prayer (2), client is dealing with crisis or an anxiety attack (2), client believes in the power of prayer (1), 
client is dying (1), social worker explains and obtains permission in advance (1), prayer fits within client's spiritual orientation (1), client is dealing with addiction (1), social worker shares the same religion with client (1), social worker is a pastoral counselor (1), form of prayer honors the tradition and spiritual orientations of ethnic groups (1), client is a victim of "cult" abuse (1).

Among people who expressed opposition to prayer in social work practice, 3 were opposed to the idea that clients should rely on prayer or faith alone for help. Three stated that it is inappropriate to pray during sessions paid for by insurance companies, in governmental programs, or in other publicly funded programs. One opposed praying for rewards; another opposed praying for physical healing. One person explained that social workers should not make decisions about what is ultimately best for the client's wellbeing, so they should not try to alter her or his reality with prayer or visualizations. One expressed concern that prayer could be used as a form of resistance to change. One stated that prayer should be left to clergy.

Another good example of controversy and caution is the practice of healing touch. This is especially significant because physical contact with clients (such as by massage) is one of the few specific helping practices that is explicitly cautioned about in the NASW Code of Ethics, Ethical Standard 1.10 on Physical Contact (National Association of Social Workers, 1999). In the quantitative portion of the survey, this was the activity with the lowest frequency of support as an activity actually done (14.6\%) and as something appropriate (24.4\%; Canda \& Furman, 1999, p. 261). Qualitative responses reflected this concern.

Eight people who supported reiki (a type of healing energy work that involves passing the hands close to the body) or healing touch believed that social workers who practice these techniques must be trained as a reiki practitioner, massage therapist, pastoral counselor, or licensed in other ways. Another three stated that supportive touch such as holding hands and touching the shoulder could be an appropriate way of body contact with clients. One said that she or he asks for a client's permission before touching; another emphasized the importance of thorough assessment before using healing touch. One person expressed concern about the potential for abuse of vulnerable clients through healing touch. One gave an example of a dying patient who is feeling alone as an appropriate situation for touch. Four respondents were totally opposed to the Christian practice of "laying on of hands" in social work practice. One said that no physical contact is appropriate.

Finally, we can examine concerns about social worker selfdisclosure as a helping activity. Fifty people commented about self-disclosure. Of these, 18 said that the social worker should never disclose his or her views about spirituality. One said that disclosure might rarely be appropriate. Thirty-one others indicated conditions under which self-disclosure about one's spiritual perspective may be appropriate. The most common were (a) worker can disclose per client's request; (b) worker can disclose if it is appropriate or relevant in the context of therapeutic dialogue; (c) worker should disclose to inform clients of his or her frame of reference for practice; (d) worker should be cautious to disclose only a limited amount of information about one's own views on religion or spirituality (reasons unspecified); (e) worker can disclose his or her own spiritual views (no specific conditions stated); (f) worker can disclose if his or her personal views support those of the client or are similar; (g) worker can disclose his or her views for the purpose of comparison or as an example of possibilities.

\section{Ethical Reflections on Conditions for Determining When Activities Are Appropriate}

Canda and Furman (1999) expanded Canda's (1990a) earlier set of ethical guidelines about using prayer in social work to all explicit spiritually oriented helping activities. This provided a basis for code categories of data analysis pertaining to conditions determining when such activities are appropriate. As we have already seen, in keeping with the Canda and Furman framework, many respondents identified the importance of ascertaining clients' interest and goals through general assessment and direct questioning about various spiritually oriented helping activities. Five hundred fifty-one people commented about the inappropriateness of imposing spiritual beliefs and practices that are inconsistent with the client's spiritual perspective. One hundred seventynine people emphasized the importance of engaging in spiritually oriented practices only in a way that fits the timing of clients' growth process and development of needs and goals.

The Canda and Furman (1999) framework emphasizes the importance of establishing a relationship of empathy, rapport, respect, and mutual understanding regarding spirituality before engaging in explicit spiritually oriented activities with clients. Eighty-five respondents made comments consistent with this. Additional crucial components of a spiritually sensitive helping relationship include self-awareness, knowledge, competency, and commitment to professional values on the part of the social worker. There were numerous comments in support of these attributes. For example, as the previous section on competence and education indicated, there were 332 comments supporting the importance of worker competency for ethically appropriate practice.

About 600 people commented on the importance of social workers remaining faithful to the NASW Code of Ethics and broad ethical principles such as client self-determination. The following are the most common examples: (a) "Worker should not promote or impose spiritual beliefs and practices that are outside of the client system"; (b) "Worker should respect and be sensitive to client's religious beliefs and practices"; (c) "Worker should not be judgmental about client's religious beliefs and practices"; (d) "Worker should support client's religious beliefs and practices"; (e) "Worker should operate based on the principle of honoring client's self-determination"; (f) "Worker should operate on fundamental social work principles and ethics" (not specified). 
Forty-four people commented on the importance of developing clear self-awareness as a basis for addressing spirituality in practice. Most of these (24) said that the social worker must be clear about his or her own spiritual belief system, values, views, and practices. Other issues of self awareness included biases related to spiritual issues; level of skills in handling these issues in practice; the state of one's own spiritual development and growth; level of comfort in handling these issues in practice; the role that spirituality plays in his or her life; and one's own spiritual history. Respondents explained the following reasons why it is important to cultivate self-awareness: to keep his or her own bias in check; to prevent his or her own beliefs from "imposing," "intruding," "interfering," or "impeding" the helping process; to be able to observe how his or her own beliefs impact the helping process and clients; to separate personal issues from professional practice; to effectively handle countertransference; to avoid judgmental reactions.

\section{Implications for Social Work Education and Practice}

The current statement of Educational Policy and Accreditation Standards of the Council on Social Work Education (2001) supports the importance of addressing ethical issues about spirituality within social work education. It states that a purpose of education is to prepare students for competent practice that is nondiscriminatory, respectful, knowledgeable, and skillful with regard to religion, along with other types of diversity. It further states that foundation-level program objectives and content must include values, ethical standards, and principles as presented in the NASW Code of Ethics and should provide human behavior theory and knowledge pertaining to spiritual development. Considering that studies have shown most practitioners likely have not received much educational preparation about spirituality or approaches to ethical decision making in relation to it, there is urgency for wide dissemination of education on spirituality via academic degree programs (coursework and practica), continuing education courses, agency in-service training, and practice supervision. It is hopeful that courses on spirituality and religion have been increasing rapidly in MSW programs nationally during the past 10 years (Russel, 1998; R. Russel, personal communication, May 18, 2001).

Although the NASW Code of Ethics provides some broad guidance in this area, it leaves many things unspecified. The Code does not give specific standards for what spiritually oriented activities may be appropriate or inappropriate, depending on multiple factors that constitute a specific practice context, a practitioner's training and spiritual perspective, and the client's situation. For example, as mentioned previously, most respondents in the quantitative portion of the survey did not believe that touching clients for healing purposes was appropriate. Yet, as qualitative comments point out, there can be valuable qualities to touching (or near touching) to indicate respect and caring or for spiritually based practices such as reiki. The Code indicates that there can be legitimate reasons for touching, but implies that touching is done at risk of psychological harm or cultural inappropriateness to the client. The Code does not clarify how to decide when and how touching in spiritually based helping practices may be appropriate.

However, comments of respondents in this study illustrate that many are influenced by broad principles and values consistent with the NASW Code of Ethics. Many articulated specific considerations for deciding whether to address spirituality in practice and whether to engage in specific spiritually oriented activities, such as prayer. Of the many hundreds of responses, there are very few that could be considered as possible violations of the Code. Indeed, the quantitative data revealed that less than $9 \%$ of all survey respondents believed that integrating religion and spirituality into social work practice conflicts with the NASW Code of Ethics or the mission of social work. It is reassuring that so many respondents demonstrate concern and thoughtfulness about the ethical issues involved in dealing with spirituality. The major lack revealed in their comments is that no one referred to any formal frameworks or educational preparation that might help in making such decisions. Given that most respondents in the quantitative portion of the survey indicated that they had little or no educational preparation for dealing with spirituality and that they questioned practitioners' preparedness to do so, there is clearly a need for greater awareness of ethical guidelines tailored to the topic of spirituality in social work education.

There are a few types of responses that raise particular ethical concerns. For example, only 1 respondent addressed the potential for covert influence over clients if the social worker prays for them privately without their informed consent. This is an issue raised in other studies on the ethics of spirituality in social work (Canda \& Furman, 1999; Sheridan, 2000; Sheridan \& Amato-von Hemert, 1999). Considering that there is increasing evidence in the medical field that prayer for others may indeed influence health outcomes (e.g., Dossey, 1993; Koenig, McCullough, \& Larson, 2001; Larson \& Larson, 1994), and many people at least believe it can, Canda and Furman's caution is apropos: Hidden manipulative spiritual agendas, even when well-intentioned, should not be used in spiritually sensitive practice. No social worker can reasonably claim to have omniscient insight into what is ultimately best for any client. If one believes that prayer can influence a client, then it seems that it is necessary to seek the client's permission to pray for him or her in a way that seeks a particular outcome. Another alternative is to pray in an "open, humble, and compassionate" way "for the client's support and healing according to the client's own best interests and spiritual path. One leaves it to the wisdom of the divine and the choices of the client to work out 
the specifics" (Canda \& Furman, 1999, pp. 265-266). Although only 1 respondent made a similar comment, this guideline for private use of prayer by social workers to help clients is consistent with respondents' other numerous comments on conditions for appropriate prayer in general.

In this study, there is a wide variety of opinion about whether and how practitioners should use their own personal spiritual backgrounds to impact the helping process, for example, through self-disclosure and special knowledge and skills pertaining to particular religious and nonreligious perspectives and practices. The comments of people who set conditions for appropriate self-disclosure seem consistent with common ethical principles. However, the presence of 22 comments totally opposed to self-disclosure raises the concern that some social workers may be holding a rigid stance that inhibits establishment of a spiritually sensitive relationship and may unnecessarily restrict certain actions that could be helpful to clients. For example, it may sometimes be necessary for the social worker to disclose spiritually based value positions and backgrounds that could be helpful in establishing rapport with the client. It may also be necessary sometimes to self-disclose in order for the client to make an informed decision about whether to work with a particular social worker because of inherent conflicts of spiritual perspective, values, and practice approach (Bullis, 1996; Loewenberg, 1988).

It may be that lack of educational preparation and opportunity for debate and sorting this through within social work education contributes to this suspicion of self-disclosure on the part of some social workers. Another factor that might influence this is the theoretical perspective on practice held by the practitioner. For example, Freudian-derived psychodynamic practice models are highly concerned about transference and countertransference and tend to discourage self-disclosure. In contrast, some existential and empowerment approaches to practice emphasize self-disclosure as relevant to client benefit in the context of a relationship based on mutuality, honesty, and collaboration. These types of theoretical issues could be addressed in human behavior in the social environment courses, practice courses, practicum supervision, and professional practice supervision.

Another area of concern relates to a small number of comments that might reflect religious discrimination that is prohibited by the NASW Code of Ethics and federal law. When respondents indicated caution about addressing spirituality in practice, they appropriately discussed the importance of not imposing the social worker's own religious agenda. But it is interesting to note that when specific instances of inappropriate uses of religiously based activities are given, the examples almost always refer to Christian activities (e.g., evangelization, laying on of hands, reading the Bible). It may simply be that these examples were given because the most common religious practices in this country are Christian. However, it might be that some social workers are prone to think of Christian examples of misuse because of a negative predisposition (Ressler \& Hodge, 2000). For example, all five comments in opposition to the use of religious and spiritual writings in social work specify that the Bible should be off limits. This not only excludes a potentially valuable resource for Jewish and Christian clients, it also implies that these respondents might consider the Bible to be more detrimental than other spiritual writings.

The qualitative data in this study do not warrant any conclusions about the general pervasiveness or motivations of the few opinions about which we have raised ethical concerns. However, these opinions further illustrate the importance of discussion about ethical issues regarding spirituality so that practitioners can sort out possible limitations in their perspectives and avoid unethical practices.

Respondents' comments about ethical decision making in practice support the rationale of the Canda and Furman (1999, p. 264) framework for "Ethical Considerations for Using Spiritually Based Activities in Social Work." Studies by Sheridan and Amato-von Hemert (1999) and Sheridan (2000) also indicate the usefulness of this framework. It could be helpful for social work educators, practicum instructors, practice supervisors, and continuing education trainers to use the Canda and Furman framework in discussions of cases as a starting point for sorting through decisions about how to address spirituality in practice. This framework could be applied to case examples for dealing with religion in social work practice (Corey, Corey, \& Callanan, 1998; Linzer, 1999; Scales et al., 2002). In addition, the suggestions of practitioners reported in this study would be a useful complement to that framework in these discussions to help students and practitioners consider a wide range of factors. The Canda and Furman framework emphasizes the importance of social workers' deep personal reflection and dialogue with colleagues and clients in the process of sorting through ethical decision making about spirituality in social work. This may include challenging the social worker's values and behaviors that might be inconsistent with professional ethics as well as questioning the possible limitations, biases, and ambiguity inherent in formalized professional ethics. These ethical complexities and nuances are well illustrated in a recent audiotaped continuing education course on ethical issues in addressing spirituality in clinical practice (On Good Authority, 2003) that includes interviews by Barbara Alexander, with Terry Northcut, Frederic Reamer, Edward R. Canda, and Dennis Haynes.

More research is needed on the ways that practitioners make ethical decisions for addressing spirituality in practice. The present study relies on brief comments in response to open-ended questions on a survey form. It does not reveal the detailed thinking, feelings, and behaviors of social workers as they sort through ethical dilemmas in their daily practice situations. Future qualitative studies would contribute to this knowledge by using ethnographic and naturalistic methods that can explore this in more depth. 


\section{References}

Anderson, G. R. (1983). Medicine vs. religion: The case of Jehovah's Witnesses. Health and Social Work, 8, 31-38.

Bullis, R. K. (1996). Spirituality in social work practice. Washington, DC: Taylor \& Francis.

Canda, E. R. (1990a). A holistic approach to prayer for social work practice. Social Thought, 16, 3-13.

Canda, E. R. (1990b). Spiritual diversity and social work values. In J. J. Kattakayam (Ed.), Contemporary social issues (pp. 1-20). Trivandrum, India: University of Kerala.

Canda, E. R., \& Furman, L. (1999). Spiritual diversity in social work practice: The heart of helping. New York: Free Press.

Canda, E. R., Nakashima, M., Burgess, V., Russel, R., \& Barfield, S. T. (2003) Spiritual diversity and social work: A comprehensive bibliography with annotations (2nd ed.). Alexandria, VA: Council on Social Work Education.

Cnaan, R. A., Wineburg, R. J., \& Boddie, S. C. (1999). The newer deal: Social work and religion in partnership. New York: Columbia University Press.

Corey, G., Corey, M. S., \& Callanan, P. (1998). Issues and ethics in the helping professions. Pacific Grove, CA: Brooks/Cole.

CSWE Online Publications: Social Work and Spirituality Resources, retrieved February 4, 2004, http://www.cswe.org/spirituality/

Council on Social Work Education. (2001). Educational policy and accreditation standards. Alexandria, VA: Author.

Derezotes, D., \& Evans, K. (1995). Spirituality and religiosity in practice: Indepth interviews of social work practitioners. Social Thought, 18, $38-56$.

Dossey, L. (1993). Healing words: The power of prayer and the practice of medicine. San Francisco: HarperSanFrancisco.

Dudley, J. R., \& Helfgott, C. (1990). Exploring a place for spirituality in social work curriculum. Journal of Social Work Education, 26, 287-294.

Ellor, J. W., Netting, F. E., \& Thibault, J. M. (1999). Religious and spiritual aspects of human service practice. Columbia: University of South Carolina Press.

Erlandson, D. A., Harris, E. L., Skipper, B. L., \& Allen, S. D. (1993). Doing naturalistic inquiry: A guide to methods. Newbury Park, CA: Sage.

Joseph, M. V. (1988). Religion and social work practice. Social Casework: The Journal of Contemporary Social Work, 69, 443-452.

Koenig, H. G., McCullough, M. E., \& Larson, D. B. (2001). Handbook of religion and health. New York: Oxford University Press.

Larson, D. B., \& Larson, S. S. (1994). The forgotten factor in physical and mental health: What does the research show? Baltimore: National Institute for Healthcare Research.

Lincoln, Y., \& Guba, E. (1985). Naturalistic inquiry. Beverly Hills, CA: Sage.

Linzer, N. (1999). Resolving ethical dilemmas in social work practice. Boston: Allyn \& Bacon.

Loewenberg, F. M. (1988). Religion and social work practice in contemporary American society. New York: Columbia University Press.

Marshall, C., \& Rossman, G. B. (1999). Designing qualitative research (3rd ed.). Thousand Oaks, CA: Sage.

Mattison, D., Jayaratne, S., \& Croxton, T. (2000). Social workers' religiosity and its impact on religious practice behaviors. Advances in Social Work, 1, 43-59.

Nash, M., \& Stewart, B. (Eds.). (2002). Spirituality and social care: Contributing to personal and community well-being. London: Jessica Kingsley.
National Association of Social Workers. (1999). NASW Code of Ethics, revised. Washington, DC: Author.

On Good Authority. (2003). Ethics V: Spiritual issues in clinical practice. Audiotape, Galena, IL: Author. Retrieved from www.ongoodauthority.com

Patel, N., Naik, D., \& Humphreys, B. (Eds.). Visions of reality: Religion and ethnicity in social work. London: Central Council for Education and Training in Social Work, 1997.

Ressler, L. E., \& Hodge, D. R. (2000). Religious discrimination in social work: An international survey of Christian social workers. Social Work and Christianity, 27, 49-70.

Russel, R. (1998). Spirituality and religion in graduate social work education. In E. R. Canda (Ed.), Spirituality and social work: New directions (pp. 15-29). Hazleton, PA: Haworth Press.

Scales, T. L., Wolfer, T. A., Sherwood, D. A., Garland, D. R., Hugen, B, \& Weaver Pittman, S. (Eds.). (2002). Spirituality and religion in social work practice: Decision cases with teaching notes. Alexandria, VA: Council on Social Work Education.

Sheridan, M. J. (2000, February). The use of spiritually-derived interventions in social work practice. Paper presented at The Annual Program Meeting of the Council on Social Work Education, New York.

Sheridan, M., \& Amato-von Hemert, K. (1999). The role of religion and spirituality in social work education and practice: A survey of student views and experiences. Journal of Social Work Education, 35, 125-141.

Sheridan, M., \& Bullis, R. K. (1991). Practitioners' views on religion and spirituality: A qualitative study. Spirituality and Social Work Journal, 2, 2-10.

Sheridan, M., Bullis, R., Adcock., C., Berlin, S., \& Miller, P. (1992). Practitioners' personal and professional attitudes and behaviors toward religion and spirituality: Issues for social work education and practice. Journal of Social Work Education, 28, 190-203.

Sheridan, M., Wilmer, C., \& Atcheson, L. (1994). Inclusion of content on religion and spirituality in the social work curriculum: A study of faculty views. Journal of Social Work Education, 30, 363-376.

Sherwood, D. A. (1998). Spiritual assessment as a normal part of social work practice: Power to help and power to harm. Social Work and Christianity, 25, 80-99.

Van Hook, M., Hugen, B., \& Aguilar, M. (Eds.). Spirituality within religious traditions in social work practice. Pacific Grove, CA: Brooks/Cole, 2001.

York, G. Y. (1987). Religious-based denial in the NICU: Implications for social work. Social Work in Health Care, 12, 31-45.

Edward R. Canda is professor and chair of the PhD program at the School of Social Welfare, University of Kansas. Mitsuko Nakashima is assistant professor at the University of Maryland School of Social Work. Leola Dyrud Furman is emeritus associate professor at the School of Social Work, University of North Dakota at Grand Forks. Correspondence regarding this article may be addressed to the first author at edc@ku.edu or the School of Social Welfare, University of Kansas, Lawrence, KS 66044-3184.

Authors' note. The authors thank the School of Social Work at the University of North Dakota at Grand Forks and the University of Kansas School of Social Welfare for funding that supported this research.

Manuscript received: December 2, 2002

Accepted: October 2, 2003 